Villaplana Ruiz, Virginia.

Profesora e investigadora en la Universidad de Murcia, Facultad de Comunicación y Documentación. Miembro del consejo editorial de la revista científica Arte y Políticas de Identidad Editum y del grupo de investigación Las Lindes.

\title{
La investigación extradisciplinar en artes visuales: prácticas colaborativas y aprendizajes comunes. (Hacia una nueva relación en las ciencias sociales. La comunicación, el arte y la educación en cuestión).
}

TIPO DE TRABAJO

Comunicación invitada.

PALABRAS CLAVE

Media art, Investigación-acción, Ciencias Sociales, Comunicación.

KEY WORDS

Media art, Action Research, Social Sciences, Comunication.

\section{RESUMEN}

En este ensayo se plantean ciertas problemáticas de la reivindicación de la investigación artística en las artes visuales, no como objeto de un conocimiento, sino como una forma de conocimiento en sí misma. Las cuestiones que se plantean apuntan a la construcción de un territorio sobre los "qué" y los "cómo" para reubicar un posible la investigación artística en el ámbito académico y su relación con las ciencias sociales, la comunicación y la educación.

\section{ABSTRACT}

This essay raises certain problems that claim artistic production, not as objects of knowledge, but as a form of knowledge itself. The issues raised are to build a territory about the "what" and " how " to relocate to possible territory of artistic research in academia and its relation to the social sciences, communication and education.

\section{CONTENIDO}

Introducción. Anotaciones al margen.

El origen de este ensayo está en mi participación como ponente en el II Congreso Internacional de Investigación en Artes Visuales organizado por ANIAV, realizado en la Universidad Politécnica de Valéncia en julio de 2015. En este encuentro planteamos un panel con la propuesta de enfocar la necesidad de reformular saberes y señalar un debate en torno a la investigación en artes visuales. Las cuestiones que nos interesaron apuntan hacia los "qué" y los "cómo" necesarios hoy para reubicar un possible territorio de la investigación artística. Al situarnos en este territorio se hace necesaria esbozar un recorrido que nos lleve a una nueva relación entre las ciencias sociales, la comunicación, el arte y la educación. Y por otra parte, concebir la investigación extradisciplinar en artes visuales dentro de un territorio de prácticas colaborativas y aprendizajes comunes. 
La comunicación, el arte y la educación en cuestión retoman una serie de reflexiones teóricas sobre la experiencia estética, la praxis, los aprendizajes en las prácticas colaborativas y participativas. Estas reflexiones emergen en este caso con la intención de recopilar los recorridos y despliegues de mi trabajo en el arte y la educación. Estos recorridos comparten una doble condición de acción/posibilidad como nexo de una poética conscientemente inacabada. Esta poética entre la praxis y la teoría contienen a su vez estos interrogantes comunes hacia: los saberes situados del arte, las narrativas de género, los estudios culturales y las pedagogías críticas.

El impulso que mueve la escritura de estas anotaciones sin margen a su vez, debo decir que es lugar compartido con otras artistas que en España simultáneamente a su propuesta de entender la práctica artística como un área de investigación y experimentación en las artes visuales, también comprometen su labor profesional como educadoras o profesoras en diversos espacios educativos de producción de conocimiento y saberes. Con frecuencia transitamos los espacios reales que comprenden la enseñanza formal, la educación secundaria obligatoria, la universidad o la formación profesional en los que puede detectarse la insuficiente presencia de las enseñanzas curriculares relacionadas con: la alfabetización visual y escrita frente a brecha social existente en el libre acceso de recursos simbólicos, culturales y en la adquisición de códigos expresivos, estéticos y comunicativos.

\section{Desarrollo. Imagenes y acciones en la búsqueda de un compromiso o distracción}

"Quiero que saques tu teléfono móvil. Que enciendas la cámara de vídeo. Que ahora grabes cualquier cosa durante un par de segundos. Sin cortes. Te está permitido moverte, panear y hacer zoom. Y utilizar solo los efectos que vienen por defecto en el aparato. Sigue haciéndolo durante un mes, cada día. Ahora detente. Escucha. Empecemos con una tesis secilla: lo que antes era trabajo se está convirtiendo cada vez más en una ocupación. (...) Una ocupación no necesariamente implica una remuneración, puesto que se considera que el proceso contiene su propia gratificación. No tiene otro marco temporal que no sea el propio transcurrir del tiempo. No se centra en un productor/trabajador, si bien incluye personas que consumen, reproducen, que incluso destruyen, derrochan tiempo y espectadoras: básicamente, cualquiera que busque distracción o compromiso" (La voz de Hito Steyerl en el libro LoS condenados de la pantalla, 2014)

La investigación-acción participativa: extradisciplinariedad y posiciones críticas.

Las áreas de debate que las artes visuales, las pedagogías feministas y la cultura visual digital están vislumbrando se basan sobretodo en una tradición feminista de la investigación-acción participativa, por tanto, incluyen la acción comunicativa, pedagógica o educativa como una herramienta de investigación y acción. Pienso que todo ello debería de hacernos pensar e imaginar de nuevo ese lugar entre el arte, la comunicación y la educación. Algunas de las ideas que avanzo deseo situarlas en las siguientes líneas de trabajo. La creación de contenidos educativos, culturales, artístico y sociales en la cultura visual digital que activen un proceso de aprendizaje y experimentación social. La innovación de metodologías experimentales en educación informal aplicadas el uso de las tecnologías de información. Finalmente, la producción artística colaborativa de espacios intergeneracionales de debate y la aplicación de pedagogías críticas. Y por último, la producción artística colaborativa sobre la transmisión de la memoria como expresión de la diversidad social y su traslación en la creación de narrativas e imaginarios de la historia del presente.

Las cuestiones que este ensayo aborda entre la comunicación, el arte, la educación y la pedagogía feminista parten de la necesidad de reflexionar en el contexto del II Congreso Internacional de Investigación en Artes Visuales, y sobre las nuevas formas de generar conocimiento en las prácticas artísticas colaborativas y participativas. A principios del mes de marzo inicié la redacción de este texto y buscaba imaginar un territorio falible que pudiera contener en su inmaterialidad el código fuente de un habla común. Si hiciéramos en este mismo instante el ejercicio de imaginar para imaginarnos en ese espacio de habla común podríamos empezar a interrogarnos sobre la responsabilidad de repensar una política cultural educativa que por una parte considere las nuevas formas globales que aporta la producción de conocimiento y la investigación en artes visuales. Recupero aquí las ideas entre estética feminista y praxis que Vala Walsh aportó en el texto "Testigos presenciales, no espectadoras; activistas, no académicas: la pedagogía feminista y la creatividad de las mujeres": "El proceso feminista implica la producción de conocimiento/arte útiles y accesibles. En el camino se replantean "utilidad", "usos" y "accesibilidad", rompiendo límites y jerarquías tales como estética/ética, cultura/naturaleza, arte/ecología." El proceso feminista es integrador y destaca las conexiones y continuidades que hay entre las distintas prácticas culturales y áreas de la vida social. Vala Walsh nos aporta además una definición sobre la pedagogía feminista para destacar la relevancia de la educación artística y su dimensión extradisciplinar: "La pedagogía feminista se desarrolla a través de la colaboración y la creatividad. Destaca el compartir experiencias, información, ideas, sentimientos y capacidades; el sentido de reciprocidad (...). Con su hincapié en lo interrelacional y el proceso, la pedagogía feminista encarna la oposición al dualismo sujeto-objeto que sustenta el pensamiento blanco occidental, e inevitablemente se arriesga también a ser percibida como no académica y no profesional.." ${ }^{1}$ El feminismo ofrece la posibilidad de una transdisciplinariedad sincrética e integradora que supone un reto a las relaciones de poder en la sociedad, condicionadas por el género, la raza, y la vulnerabilidad de las mujeres dentro de estas disposiciones. "La revisión y recreación de nuestras formas y relaciones sociales/culturales requiere tanto una poética como una política, y la estética es esencial para ambas. Hay que evitar los métodos académicos que dan como resultado que se discuta sobre las mujeres o sobre las artistas meramente como "significantes», pues esto se limita a repetir el interés masculino de la Academia por hacer progresar las fronteras del conocimiento, con las mujeres sirviendo de material secundario para este proyecto «neutral». (...) El arte debe ser aclamado como testimonio cotidiano de «la no violencia como poder», y como base para la comunidad, no para la separación." ${ }^{2}$ En este eje conviene 
recordar la propuesta de Brian Holmes en su texto "Investigaciones extradisciplinares. Hacia una nueva crítica de las instituciones" y cómo lo extradisciplinario se propone para una nueva crítica institucional: "La ambición extradisciplinar consiste en llevar a cabo investigaciones rigurosas en terrenos tan alejados del arte como son las finanzas, la biotecnología, la geografía, el urbanismo, la psiquiatría, el espectro electromagnético, etc., para impulsar en estos terrenos el «libre juego de las facultades» y la experimentación intersubjetiva que caracterizan al arte moderno y contemporáneo, pero también para tratar de identificar, dentro de esos mismos dominios, los usos espectaculares o instrumentales que con tanta frecuencia se hacen de las libertades sorpresivas y subversivas del juego estético, como hace el arquitecto Eyal Weizman de manera ejemplar cuando investiga la apropiación militar israelí y estadounidense de estrategias arquitectónicas cuya concepción original era subversiva. Eyal Weizman desafía a lo militar en su propio terreno con sus mapas de infraestructuras de seguridad en Israel; pero regresa con elementos nuevos para el examen crítico de lo que había sido su disciplina exclusiva." ${ }^{3}$

En este sentido es preciso comprender la investigación arte-comunicativa-educativa, los espacios de interacción que integran procesos de subjetividad complejos y en los usos sociales de la memoria. Todo ello me llevó hace unos años a desarrollar la metodología experimental de la mediabiografía ${ }^{4}$. A partir de esta metodología que se centra en la memoria transactiva también exploro experiencias entre arte, comunicación comunitaria, salud y antipsiquiatría en la tercera edad (Alzeihmer), grupos con daño cerebral adquirido, cuidados del cuerpo y condiciones de vida con grupos de adolescentes y diversidad funcional. El proyecto de arte y educación Diarios de Sueños Intermitentes (Departamento de educación y acción cultural Musac/ Centro de Inserción Social de León) exploró la expresión de la identidad de género y la narración de la biografía con grupos de mujeres y hombres en situación de privación de libertad. En la actualidad como parte de Real-Code ${ }^{5}$ y junto a otros investigadores participo en el proyecto "Ciudadanía y Educomunicación" para el estudio de la vulnerabilidad en medios de comunicación, la formación, la comunicación en las comunidades y en grupos de prioridad de atención social. La idea que se persigue es analizar cómo informan los medios de comunicación sobre "los llamados" grupos prioritarios de atención social (personas con diversidad funcional, enfoque de género, migrantes, infancia y juventud), qué grado de vulnerabilidad se construye sobre su representación en los mass media y cómo imaginan otra la posibilidad de representación y creación de formas de autorepresentación linkadas a la noción Imaginación Civil que Ariela Ariella propone en su libro The Civil Imagination. A Political Ontology of Photography ${ }^{6}$. La Imaginación Civil saca a la luz la forma en la que las imágenes pueden tanto reforzar y ser parte de una resistencia a la realidad opresiva impuesta sobre las personas representadas.

\section{Conclusiones}

Cuando hablamos de Investigación Artística o Investigación basada en las Artes, no nos referimos a la aplicación de los métodos científicos o de análisis de las ciencias sociales en la práctica artística, sino más bien a las posibilidades de negociar otros modos de producir y aplicar las condiciones y las políticas en las que el pensamiento artístico se enmarca socialmente.

De este modo, la investigación artística hay que entenderla como una forma de análisis y reflexión, pero fundamentalmente de acción, capaz de redefinir y reubicar la práctica artística en el presente. La primera conclusión es que la retórica en torno a la Sociedad de la Información o Economía del conocimiento, ha supuesto un cambio de paradigma que ha asimilado fácilmente la práctica artística para cubrir determinadas plusvalías simbólicas en las agendas institucionales. En este sentido, el carácter investigador o I + D aplicado a las artes visuales está siendo un recurso cada vez más utilizado de acuerdo a los criterios determinados por las industrias creativas. $Y$ corre el peligro de ser adaptado como una tendencia en el mercado del conocimiento. La segunda conclusión resulta de considerar el siguiente hecho, el componente investigador del arte ya se considera en algunos países una clave indispensable, tanto para las políticas públicas innovadoras como para la promoción de la llamada clase creativa. Sin embargo, este fenómeno no anula el valor de las aportaciones específicas del arte en el conocimiento científico, tecnológico, social y económico. En consecuencia, si en algo se debería diferenciar la investigación artística es precisamente en su capacidad de inocular disensión en relación a la supuesta neutralidad con que a menudo se fundamenta la producción de conocimiento en otros ámbitos del pensamiento. Finalmente se puede concluir que lejos de manifestarse siguiendo los protocolos académicos clásicos, la Investigación Artística que aquí se propone tiene como objetivo revalidar el conocimiento colectivo en relación a las metodologías científicas. En su lugar, la Investigación Artística se acerca a las metodologías de investigación no lineales y a las formas de escritura dialógica a través de la construcción de narrativas, en consonancia con las epistemologías y metodologías feministas, la investigación Acción-Participante y la generación de conocimientos situados. 


\section{FUENTES REFERENCIALES.}

- Ahmed, S. (2004). The Cultural Politics of Emotion. London: Routledge Edinburgh University Press.

- Bauer P. and Kidner D. editors (2013): Working Together: Notes on British Film Collectives in the 1970s, Focal Point Gallery, London.

- Colectivo Subtramas (2014): «Cuatro preguntas para una utilidad que está por venir». Un saber realmente útil, Museo Nacional Reina Sofía, Ministerio de Educación, Cultura y Deportes, 2014.

- De Certeau, Michel. La invención de lo cotidiano. 2 vols. México, D. F.: Instituto Iberoamericano, 2006.

- CHOMSKY, Noam (2005): Sobre democracia y educación, Volumen I y II. Barcelona: Paidós.

- GRZNIC, Marta i REITSAMER, Rosa (eds) (2008): New Feminism. Worlds of Feminism, Queer and Networking Conditions. Viena: Löcker.

- STEYERL, Hito: "Los condenados de la pantalla". Editorial Caja Negra. Buenos Aires 2014. Traducción: Marcelo Expósito. Título Original: The Wretched of the Screen.

ARTíCULOS (Fecha de consulta 12 de junio, 2015)

- Hito Steyerl, “¿Una estética de la resistencia? La investigación artística como disciplina y conflicto”, 2010. http://eipcp.net/transversal/0311/steyerl/es

- Malo, Marta (2004): “Nociones Comunes: del análisis institucional a experiencias contemporáneas entre investigación y militancia”. http://eipcp.net/transversal/0707/malo/es/print

- ZAMORA, José A. - Docencia e investigación en la "sociedad del conocimiento". Una aproximación crítica - VVAA: Espai en Blanc 7-8: El combate del pensamiento (ISBN 9788472904927) - Edicións Bellatera - 2010 - 11pp.

\section{WEBGRAFÍA COMENTADA. SELECCIÓN DE PROYECTOS ARTE, COMUNICACIÓN Y EDUCACIÓN}

Colectivo Chto Delat , Moscú/San Petesburgo

La plataforma Chto Delat integra a artistas, filósofos, investigadores sociales, activistas y a todas aquellas personas cuyo objetivo es la producción crítica e independiente de proyectos artísticos basados en la investigación, la publicación, la educación y el activismo. Todas las iniciativas de Chto Delat se basan en los principios de autoorganización, solidaridad y colectivismo, manifiestándose a través de la coordinación política de grupos de trabajo. Organiza y apoya a redes de ayuda mutua con todos aquellos grupos de base que comparten los principios del internacionalismo, el feminismo y la igualdad.

- Colectivo Etcétera Federico Zukerfeld \& Loreto Garín Argentina,

Fundadores del colectivo Etcétera y miembros del movimiento Internacional Errorista.

- La cátedra experimental sobre producción de subjetividad (CXPDS). Rosario, Argentina , Proyecto militante que articula prácticas de autoformación, coinvestigación e innovación teórica, con el objeto de producir formas constituyentes de militancia universitaria que tengan como terreno existencial los problemas del saber y el pensamiento, de su producción y de su capacidad de producir efectos políticos en las experiencias de autoorganización social. http://eipcp.net/transversal/0707/catedraexperimental/es

Las Lindes. Grupo de investigación y acción acerca de educación, arte y prácticas culturales. Las Lindes surgió en 2009 hasta la actualidad como respuesta a una inquietud compartida por distintos agentes de la educación que se enfrentaban a la dificultad de generar un relato diferente al dominante sobre las prácticas educativas críticas al tiempo que intuían la necesidad de construir una comunidad educativa que reflexionase sobre la esencia de la educación. Desde el inicio del proyecto partimos de la convicción de que la educación es el lugar privilegiado desde el que construir un proyecto común de futuro y nos planteamos el trabajo desde la pregunta y el cuestionamiento continuo de nuestras prácticas y de nuestros referentes teóricos como una posibilidad de dar cuerpo a una comunidad para reflexionar, compartir y dirigir nuestras preocupaciones y deseos. http://ca2m.org/es/videoteca-lindes

- Sitesize. Barcelona,

Plataforma fundada en 2002 por Elvira Pujol y Joan Vila-Puig. Sitesize desarrolla proyectos colaborativos de creación y mediación cultural, centrados en la metrópolis contemporánea, con una atención especial en la región metropolitana de Barcelona. Sus ámbitos de 
interés son principalmente las prácticas de producción cultural autónoma y la investigación de nuevas geografías territoriales y paisajísticas.

Subtramas. Plataforma de investigación y de coaprendizaje sobre las prácticas de producción audiovisual colaborativas. (Colectivo formado por Diego del Pozo, Montse Romaní y Virginia Villaplana). Financiado por Ministerio de Educación, Cultura y Deporte. Proyecto de investigación en proceso enmarcado en el campo de estudio de la cultura visual digital, que impulsa la investigación y la producción colaborativa en torno a la imagen en movimiento. Para ello, Subtramas pone en valor aquellos trabajos que, desde el cine colectivo y las artes visuales, han cuestionado las relaciones entre el conocimiento y el poder, fomentando un territorio de cruce entre el arte, la democracia participativa, la educación y la vida cotidiana. http://subtramas.museoreinasofia.es/es

\section{NOTAS:}

\footnotetext{
${ }^{1}$ Vala Walsh (1998): "Testigos presenciales, no espectadoras; activistas, no académicas: la pedagogía feminista y la creatividad de las mujeres". En Katy DEEPWELL (ed.): Nueva crítica feminista de arte. Estrategias críticas. Cátedra, Madrid, pág. 112.

${ }^{2}$ Vala Walsh (1998): “Testigos presenciales, no espectadoras; activistas, no académicas: la pedagogía feminista y la creatividad de las mujeres". En Katy DEEPWELL (ed.): Nueva crítica feminista de arte. Estrategias críticas. Cátedra, Madrid, pág. 114-115.

${ }^{3}$ BRIAN HOLMES. "Investigaciones extradisciplinares. Hacia una nueva crítica de las instituciones"; "Lo extradisciplinario. Para una nueva crítica institucional". Artículo publicado en el ㄲo 28 de la revista Multitudes, 2007.

4 "Memoria colectiva y mediabiografía como transformación de los relatos culturales". Revista Científica, Arte y Políticas de Identidad, , editorial Editum de la Universidad de Murcia. Narrativas poscoloniales: globalización e identidades. Volumen: 3 . Año: diciembre 2010 pp: 87- 101. La mediabiografía es una herramienta interdisciplinar que se desarrolla en la práctica con imágenes de la memoria digital. La mediabiografía parte de las enseñanzas que puede compartir personalmente con Frigga Haug y de la lectura de su obra de ensayo en ciencias sociales sobre Memory Work.
}

${ }^{5}$ Real-Code. Red Europa América Latina de Comunicación y Desarrollo. http://www.real-code.org/es/

${ }^{6}$ Azoulay, Ariella: Civil Imagination: A Political Ontology of Photography, London: Verso, 2012. 